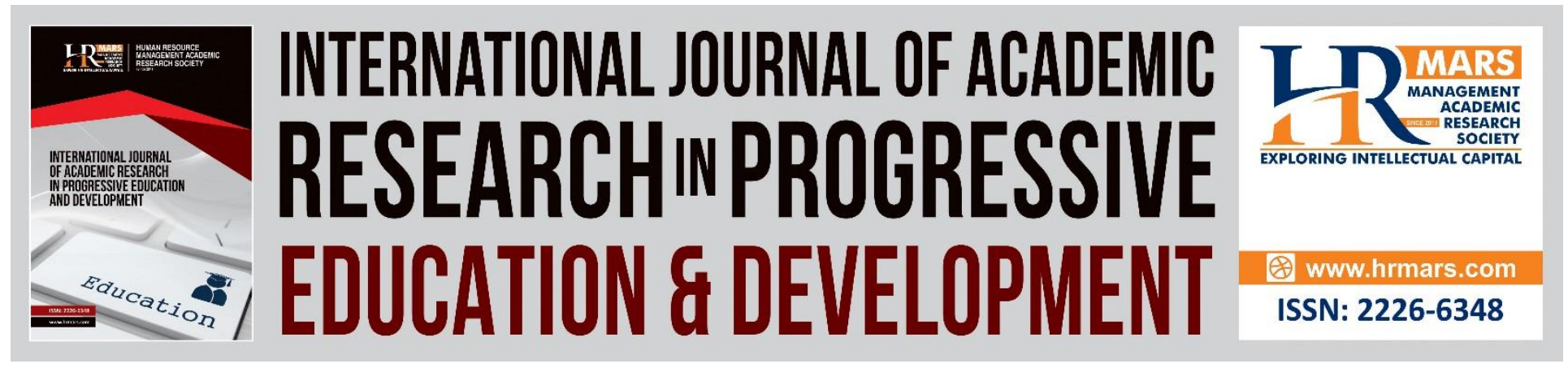

\title{
Teachers' Intention to Continue Using Virtual Learning Environment (VLE)
}

TamilMullai A/P Thannimalai

To Link this Article: http://dx.doi.org/10.6007/IJARPED/v10-i2/10135

DOI:10.6007/IJARPED/v10-i2/10135

Received: 11 April 2021, Revised: 14 May 2021, Accepted: 27 May 2021

Published Online: 07 June 2021

In-Text Citation: (Thannimalai, 2021)

To Cite this Article: Thannimalai, T. A. (2021). Teachers' Intention to Continue Using Virtual Learning Environment (VLE). International Journal of Academic Research in Progressive Education and Development, 10(2), 542-547.

Copyright: (C) 2021 The Author(s)

Published by Human Resource Management Academic Research Society (www.hrmars.com)

This article is published under the Creative Commons Attribution (CC BY 4.0) license. Anyone may reproduce, distribute, translate and create derivative works of this article (for both commercial and non-commercial purposes), subject to full attribution to the original publication and authors. The full terms of this license may be seen at: http://creativecommons.org/licences/by/4.0/legalcode

Vol. 10(2) 2021, Pg. 542 - 547

http://hrmars.com/index.php/pages/detail/IJARPED

JOURNAL HOMEPAGE

Full Terms \& Conditions of access and use can be found at http://hrmars.com/index.php/pages/detail/publication-ethics 


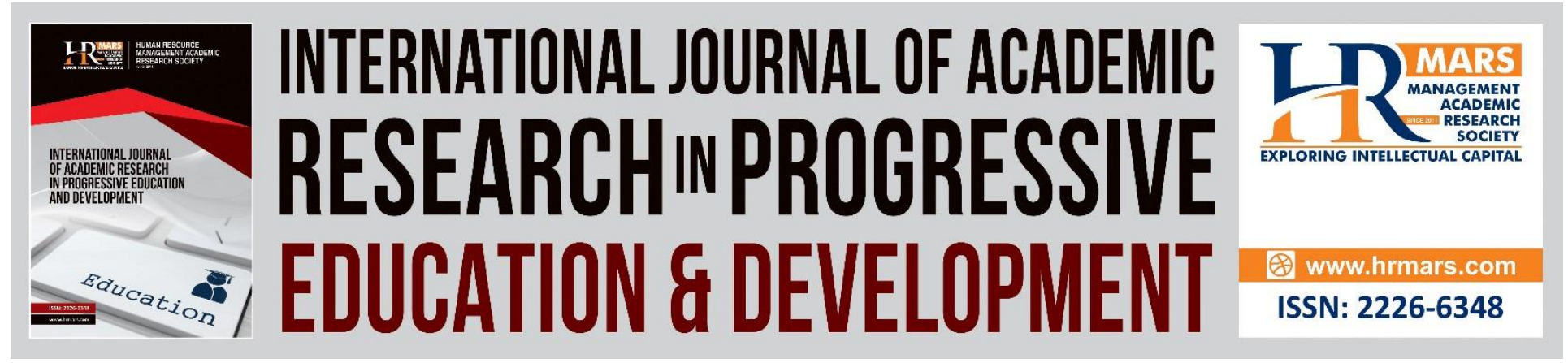

\title{
Teachers' Intention to Continue Using Virtual Learning Environment (VLE)
}

\author{
TamilMullai A/P Thannimalai
}

Faculty of Language and Communication, Sultan Idris University of Education Malaysia

\begin{abstract}
This study is entitled Teachers' Intention to Continue Using Virtual Learning Environment (VLE). This study uses two qualitative methods each with analysis of journals available from various sources that can use as well as quantitative methods by interviews and survey forms. The objective of this study was to identify teachers 'intentions to continue using the use of virtual learning (VLE). There are several challenges in this study of the use of limitations using VLE among teachers, difficulties in students, time taken in preparing materials, involvement with students and students' response to the virtual learning environment. The study found that the percentage of high-intention teachers higher higher low-intention teachers low teacher readiness to use VLE in the presence of access was moderate.
\end{abstract}

Keywords: Intention, Virtual Learning Environment, Teacher, Qualitative, Methods

\section{Introduction}

Type of system derived from successful applications of artificial intelligence is the concept of intelligent system has emerged in information technology (Molina, 2020). Intelligent systems can bring some relevant advantages in education and are extensively used in many domains (Advani, 2021). To improve the learning experience and the quality of teaching they offered the opportunity. The crises of 21st century make the virtual learning triggered such as the new normal of Pandemic COVID19 as a proved. By using virtual learning for adapting the new normal of Pandemic COVID19, Universiti Pendidikan Sultan Idris decided to continue teaching and learning. Virtual Learning Environment (VLE) is defined as allowing interactions with other participants and access to a wide range of resources using the computer-based environments that are relatively open systems (Benedetto, Cremonesi and Parenti, 2019). Online platform used for educational purposes also define as a virtual learning environment (VLE). Whether they are online courses, reading resources and informational sites with stand-alone skill assessments, or other forms of virtual learning, it encapsulates all the online environments that act as supplements to the course. As an effective medium to enhance the quality of teaching and learning VLE usually applied in schools or higher institutions. Furthermore, the development of 
sophisticated inventions of ICT tools has shifted the nature of teaching and learning including VLE.

\section{Problem Statement}

Nowadays, as blended learning and on-line learning has become common with the aid of VLE and it is the new kind of pedagogy strategies (Wegner, Minnaert \& Strehlke, 2013). In this sense, by promoting virtual learning model beyond the boundaries of time and space, by facilitating a means for learning experience management, and providing teachers and students with technology-integrated environment it has changed the traditional nature of learning approach. By promoting the dynamicity in learning especially in term of defying the barriers of time and location, the introduction of VLE into education has produced positive impacts to teachers, students, and parents. also enables users to mutually communicate to each other in a asynchronous and synchronous way (Limm, 2017). The implementation VLE technology in Malaysia, known as Google Classroom and Delima Platform was a part of educational information systems expansion initiated by Ministry of Education, Malaysia (MOE) to improve the previous version of School Net service such as VLE Frog (Cheok et al., 2017). Furthermore, the success of the degree of utilization is a crucial part of information system (IS) agreed by the most researchers. Indeed, few studies have been provided findings about the continuation of the VLE use in education the low utilization of Google Classroom VLE is closely associated to the issue of continuous usage. Therefore, this current study using survey and in-depth interview was conducted to measure Malaysian teachers' level of intention to continue using VLE technology as well as investigate the factors influencing teachers' decision to keep using VLE into teaching and learning process VLE integration into teaching.

\section{Literature Review \\ ICT for Education}

Process of teaching and learning with the aid of certain medium and technology referred as the ICT in education (Ghavifekr \& Wan Athirah, 2015). In each country around the world the level of success for ICT integration in education is totally differs. ICT use in education is effective and regularly implemented by the teachers proven by the developed countries such as Finland, Singapore, South Korea, United Kingdom, and the United States. Without any clear positive sign of revenue for the investment Malaysia are still in the beginning stage of ICT integration. Success lies on the high priority given by the government to the educational sector and Malaysia is now considered as one of the fast-growing countries in Asia. High priority in terms of policies has been given to the integration of ICT in line with the utilization of ICT in education.

Online platforms are becoming increasingly advanced due to creativity and innovation aided by the sophistication of Information and Communication Technology (ICT). At the school and higher education levels, there are various online learning initiatives.

\section{VLE Integration and its Hindrance}

VLE is a type of E-Learning system and sometimes referred as E-Learning or Learning Management System (Kalinga, 2010). That is systematically support the online learning and administrations that has implemented in various educational settings such as schools, 
universities and to training centers. It is commonly recognized as an internet-based platform that support various educational activities including online courses, quizzes, and tutorials. Web 2.0 technology that can support distance learning as well as blended learning is usually used in VLE. Capability to defy the barriers of time and location, allows asynchronous teaching and learning is the central theme of this system. The teachers and student are no longer must be physically present at the same place (Coman, Gabriel, Schmitz, Stanciu \& Bularca, 2020). Google Classroom had two type of users can choose either paid $G$ Suite Enterprise for Education tier that includes additional features, such as advanced videoconferencing features, advanced security and premium support or else just use it for free for schools that are using Google Apps for Education. By boosting the quality of Malaysian education up to the highest level will be the new hoped of public schools, students, teachers and parents will be connected in the virtual learning community. Since VLE was introduced by the Ministry of Education in 2012 Malaysian teachers have been using Virtual Learning Environment (VLE) technology in their instructional activities (Awang, Aji, Yaakob, Osman, Mukminin, \& Habibi, 2018). There is moderate level of users VLE technology among the Malaysian teachers. The percentage of the teachers with high intention to use VLE whenever they have access is higher than those with the low intention this shown the study of the teachers' intention to continue using Virtual Learning Environment (VLE) absolutely needed.

\section{Methodology}

This section describes the methods used by the researcher to obtain the results of the study. The study methodology covers the methods and approaches used to achieve the objectives and objectives of the study. All plans are well organized to ensure that researchers get complete information and data through specific methods. In this chapter the researcher will discusses in detail the design of the study, the research instrument and the methodology used in this study. The method in this study using the mix method study in which the investigation of the sequential explanatory design which has been carried out to describe the specific phenomenon. The strategy in this study type is characterized by qualitative data and followed by the quantitative data collection and analysis in a phase of the research. Organization of the report of procedures into quantitative data collection and analysis followed by qualitative data procedures.

Researchers must understand and carefully consider each of the dimensions of mixed methods design, and always keep an eye on the issue of validity to design a mixed study (Schoonenboom and Johnson, 2017). The process of selecting and constructing mixed methods research (MMR) designs has been decided a long time by the researcher. In mixed method, the qualitative data and quantitative data both used. Qualitative data such as the result from the previous study, the journal, books and academic website for the Virtual Learning Enviroment data. The data collected from the qualitative data then analyzed and applied into the study. The quantitative data is the survey use questionnaire and interview session with ten teacher that currently use VLE in their class. Based on the interview method, we can obtain background information, features and other information needed. The researcher will interview a lecture and a group of adolescents that involve in promiscuity to get the information on the issue. The researcher will also provide questions to interview respondents. Face-to-face interviews are probably the more expensive method of data collection because they take a long time, and they can take time to interact with 
respondents.In this study, the researchers also used the interview method. Interview methods are used by researchers to obtain information, especially in qualitative research. Interviews are a method in which subjects and researchers are present in the process of obtaining information. The interview that the researcher does is an academic interview that is the social interaction between the interviewer (interviewer) and the interviewee (interviewee). This social interaction aims to get as much information as possible from the interviewee and there is no element of entertainment or coercion. The interview method was chosen because it is appropriate for the study which requires the researcher to obtain information from the respondents. The interview method has a concept that can be used to obtain data to obtain information about a fact.

\section{Discussion}

In each country around the world, the level of success for ICT integration in education differs. On the contrary, without any clear positive sign of revenue for the investment other countries (especially developing countries like Malaysia, Nigeria \& Bangladesh) are still in the beginning stage of ICT integration. Nevertheless, the integration of ICT into education also triggers controversial debate among scholars, respectively in both ICT and education. Disciplines. The intention to continue using VLE among the Malaysian teachers is at the moderate level from the quantitative data. From the qualitative data also shown that the factors that has been identified through qualitative study is teachers' workload, accessibility, competency and acceptance. The percentage of high intention teachers is higher compared to low intention teachers although the teachers willingness to use VLE with the existence of access is moderate. In this study there are five challenges identified by the researcher. The challenges is limitation of using technology, difficulty in evaluating student, material preparation take times, engagement with the student and also teacher does not have the student feedback.

To immediate and future role of educators in creating a viable teaching and learning environment further and school sector education responds to the influence of computer networks and technology is central which the way academic practices in higher. Knowledge is related to social action, information is conceived as a flow of messages enabling the creation of knowledge and the process of legitimising knowledge (Justification) is a social process. The process of creating metaconceptual understanding amplifies by the driver of academic practices through virtual learning is that of the creation of one's own knowledge. Today, to creating an environment that is interactive and personalised technology resources are vital. To be more prevalent in our educational activities web-based information systems including online data resources have continued. Nowadays, the growing challenge of accessing data from a variety of sources faces by the school administrators, teachers and also student. (Greenwood, 2010).

\section{Conclusion and Future Work}

To engage students more actively in production of knowledge teachers have yet to exploit the creative power of the platform. Factors beyond teachers' control such as institutional cultures, leadership, financial, curriculum and assessment may influence or limit the uptake and impact the platform that dependent on the ability of teachers to fully exploit the technology effectively for pedagogical purposes. In general, the use of virtual learning environment is of necessity in our current educational dispensation is for schools to be able to provide inclusive and 
differentiated education. Apparently, the finding of the current study has provided the useful insight regarding the current scenario of VLE implementation in Malaysia, which should call the attention of VLE stakeholders in Malaysia for future improvement. More importantly, the finding of this study will also provide a basis for future researcher to investigate the factors that will affect the usage the VLE success among the Malaysian teachers.

\section{References}

Advani, V. (2021). What is Artificial Intelligence? How does Al work, Types and Future of it?. Retrieved 12 April from https://www.mygreatlearning.com/blog/what-is-artificialintelligence/

Benedetto, L., Cremonesi, P., and Parenti, M. (2019). A Virtual Teaching Assistant for Personalized Learning. Retrieved 12 April from ttps://www.researchgate.net/publication/331343430

Cheok, M. L., Wong, S. L., Ayub, A. F., \& Mahmud, R. (2017). Teachers' Perceptions of E-Learning in Malaysian Secondary Schools. Malaysian Online Journal of Educational Technology. 5(2). 20-33

Coman, C., Gabriel, L., Schmitz, L. M., Stanciu, C., \& Bularca, M. C. (2020). Online Teaching and Learning in Higher Education during the Coronavirus Pandemic: Students' Perspective. Sustainability 2020, 12, 10367; doi:10.3390/su122410367

www.mdpi.com/journal/sustainability

Ghavifekr, S., \& Rosdy, W. A. W. (2015). Teaching and learning with technology: Effectiveness of ICT integration in schools. International Journal of Research in Education and Science (IJRES), $1(2), 175-191$.

Greenwood, J. (2010). Using a VLE for Teaching and Learning; iCT@C, Teaching and Learning with technology. http://shareit.yhgfl.net/kirklees/holmfirthhighschool/?tag=vle Accessed 01/03/10.

Awang, H., Aji, Z. M., Yaakob, M. F. M., Osman, W. R. S., Mukminin, A., \& Habibi, A. (2018). Teachers' intention to continue using Virtual Learning Environment (VLE): Malaysian context. JOTSE, 8(4), 439-452.

Lim, F. P. (2017). An Analysis of Synchronous and Asynchronous Communication Tools in eLearning. Retrieved 12 April from https://www.researchgate.net/publication/313673458_An_Analysis_of_Synchronous_and_ Asynchronous_Communication_Tools_in_e-Learning.

Molina, M. (2020). What is an intelligent system?. Retrieved 12 April from https://arxiv.org/abs/2009.09083

Schoonenboom, J., \& Johnson, R. B. (2017). How to Construct a Mixed Methods Research Design. Kolner Zeitschrift fur Soziologie und Sozialpsychologie, 69(Suppl 2), 107-131. https://doi.org/10.1007/s11577-017-0454-1

Wegner, C., Minnaert, L., and Strehlke, F. (2013). The importance of learning strategies and how the project 'Kolumbus-Kids' promotes them successfully. European Journal of Science and Mathematics Education, 1(3). 137-143 